\title{
Virus de Varicela zoster y sus múltiples espectros clínicos. A propósito de un reporte de caso.
}

\author{
Andrea Catalina Nassar Tobón ${ }^{1 *}$, Laura Alejandra León Rivera², Neiby Johana Rivera Rojas ${ }^{3}$, \\ María Angélica Pulido Correa ${ }^{4}$ \\ ${ }^{1}$ Especialista en Neurología Clínica, Hospital Universitario Clínica San Rafael. Bogotá-Colombia \\ ${ }^{2}$ Residente de Medicina Interna II año, Hospital Universitario Clínica San Rafael, Fundación Universitaria Juan N Corpas. Bogotá-Colombia \\ ${ }^{3}$ Especialista en Neurología Clínica, Hospital Universitario Clínica San Rafael). Bogotá-Colombia \\ ${ }^{4}$ Residente de Medicina Interna II año, Hospital Universitario Clínica San Rafael, Fundación Universitaria Juan N Corpas. Bogotá-Colombia
}

\begin{abstract}
RESUMEN
Introducción: Se presenta el caso de una paciente inmunocompetente que debutó con el virus del Herpes zóster (HZ) en región preauricular y auricular por reactivación de varicela, desarrollando síndrome de Ramsay Hunt (SRH), afectación del VII par craneal derecho House Brackman II y por último, meningitis linfocitaria por el virus de la Varicela zóster (VVZ) documentado en líquido cefalorraquídeo (LCR).

Objetivo: Describir las características del VVZ y sus múltiples manifestaciones clínicas, incluyendo la presentación del SRH, con compromiso del sistema nervioso central (SNC).

Método: Se realizó la revisión de la historia clínica y extracción de los datos previo consentimiento informado, posteriormente se ejecutó una revisión bibliográfica en las bases de datos de PubMed, SCIELO, ProQuest, utilizando descriptores de Ciencias de la Salud (DeCS) y términos MeSH: Case reports, Publishing, reviews. Los artículos incluidos fueron los publicados entre enero de 2005 y febrero de 2020.

Resultados: Se identificaron las múltiples reactivaciones y complicaciones clínicas del virus del HZ. Desde un herpes zóster cervical, que luego comprometió estructuras externas del oído y finalmente tanto el sistema nervioso central como el periférico.

Discusión: El virus del herpes zóster pertenece al alfa herpes virus 3 , se presenta como una primo infección (varicela) y una infección secundaria inmunomediada por células mononucleares. Su espectro clínico incluye cuadros de encefalitis, meningitis, vasculopatías, entre otros. El caso que se describe a continuación es una paciente que presenta múltiples espectros de la varicela zóster que, si bien se presenta más en inmunosuprimidos, cierta parte lo presentan pacientes inmunocompetentes.
\end{abstract}

Palabras clave: Virus de la Varicela zoster, Síndrome de Ramsay Hunt, Parálisis facial, Meningitis linfocitaria

\section{ABSTRACT \\ Varicella zoster virus and its multiple clinical spectra. Regarding a case report.}

Introductión: We present the case of an immunocompetent patient who debuted with the Herpes Zoster virus (HZ) in the preauricular and atrial region due to reactivation of chickenpox, developing Ramsay Hunt syndrome (SRH), involvement of the right 7 th cranial nerve
House Brackman II and finally, Varicella-Zoster virus (VZV) lymphocytic meningitis documented in cerebrospinal fluid (CSF).

Objetive: To describe the characteristics of VZV and its multiple clinical manifestations, including the presentation of SRH, with involvement of the central nervous system (CNS).

Method: A review of the medical history and extraction of the data was carried out with prior informed consent, and a bibliographic review was carried out in the PubMed, SCIELO, ProQuest databases, using descriptors of Health Sciences (DeCS) and MeSH terms: Case reports, Publishing, reviews. The articles included were those published between January 2005 and February 2020.

Results:The multiple reactivations and clinical complications of the $\mathrm{HZ}$ virus were identified. From a cervical herpes zoster, which later compromised external structures of the ear and finally both the central and peripheral nervous system.

Discussion: Herpes zoster virus belongs to alpha herpes virus 3, it presents as a cousin infection (chickenpox) and a secondary infection immunomediated by mononuclear cells. Its clinical spectrum includes pictures of encephalitis, meningitis, vascular disease, among others. The case described below is a patient who has multiple spectra of varicella zoster that, although it occurs more in immunosuppressed patients, a certain part is presented by immunocompetent patients.

Keywords: Varicella zoster virus, Ramsay Hunt syndrome, Facial paralysis, Lymphocytic meningitis. Andrea Catalina Nassar Tobón andrea-nassar@juanncorpas.edu.co

Como citar: Nassar Tobón A, León Rivera L, Rivera Rojas N, Pulido Correa M. Virus de Varicela zoster y sus múltiples espectros clínicos. A propósito de un reporte de caso. Revista Cuarzo 2020;26(1):28-35.

Recibido: 04 de abril de 2020 Aceptado: 17 de junio de 2020 Publicado: 30 de junio de 2020

DOI: https://doi.org/10.26752/cuarzo.v26.n1.492 


\section{INTRODUCCIÓN}

A lo largo de la historia, se han identificado más de 80 tipos del Virus del Herpes. Sin embargo, hasta el momento, ocho de ellos, son patógenos para el ser humano. El virus del Herpes Humano contiene una doble cadena de ADN, envuelto en una cápside proteica y una envoltura de glicoproteínas. El VVZ, es una Alfa-herpes virus 3 morfológicamente igual al virus del Herpes simple y se transmite de persona a persona (1). Puede producir infecciones que no alcanzan una curación biológica durante la vida del hospedero y si pueden expresarse de manera latente con los periodos de reactivación. Dependiendo del grado de competencia inmunitaria del huésped y la naturaleza primaria o secundaria, se define su presentación y sus posibles complicaciones (2).

Dentro del espectro clínico del VVZ cabe destacar que puede manifestarse con un cuadro de encefalitis, meningitis, cerebelitis, mielitis, vasculopatías, y parálisis de los nervios craneales, incluido el síndrome de Ramsay Hunt.

Se presenta el caso de una paciente con síndrome de Ramsay Hunt, entidad clínica de presentación aguda que se desencadena por la reactivación de una exposición primaria de la varicela, la cual permanece latente en el ganglio sensorial de la raíz dorsal, ubicado en la columna vertebral y los nervios craneales (3). El cuadro clínico se caracteriza por presentar parálisis facial periférica, acompañado de vesículas en el oído (virus del Herpes zoster ótico), con implicación del nervio facial, y del vestibulococlear, generando un síndrome vertiginoso, que se puede acompañar de sordera, tinnitus y nistagmo. Puede asociarse con ganglionitis y pleocitosis en el LCR, lo que indica compromiso a nivel del SNC (3); como en el caso clínico de la paciente que se presenta.

Su incidencia, ocurre en aproximadamente uno por cada mil casos, constituye la segunda causa de parálisis facial periférica de origen no traumático; entre 4.5 y $8.9 \%$ de los casos de parálisis facial, se relaciona con el virus del Herpes zóster ótico. Su diagnóstico se realiza a partir de anamnesis y hallazgos al examen físico acompañado de ayudas diagnósticas como estudios en LCR, y neuroimágenes. El tratamiento difiere según el compromiso a nivel del SNC con aciclovir endovenoso y corticoide tópico.

\section{REPORTE DE CASO}

Se trata de una Mujer de 66 años, que ingresó al servicio de urgencias, por cuadro clínico de 7 días de evolución consistente en cefalea hemicraneana derecha, tipo picada, de intensidad $9 / 10$, que irradia a región petrosa ipsilateral y que se acompaña de náuseas, emesis de contenido alimentario y parálisis facial periférica derecha. Dentro de sus antecedentes de importancia, mencionar Hipertensión arterial y Diabetes mellitus tipo 2 no controlada, insulinorequiriente, al examen físico con asimetría facial, plejìa que compromete los músculos de la frente, desviación de la comisura labial hacia la izquierda. Dada la edad de presentación, el sexo de la paciente y las características semiológicas se consideró una cefalea con banderas rojas, por lo cual se realizó una tomografía axial de cráneo (TAC) (Imagen 1), que mostró signos de Leucoencefalopatía microangiopática, ateromas calcificados de troncos de arterias de la base sin alteraciones agudas. Además, se realizó resonancia magnética (RM) cerebral que descartó alteraciones agudas que explicaran la sintomatología de la paciente (Imagen 2 y 3 ). Se realizó punción lumbar, con líquido cefalorraquídeo, que se describe en la (Tabla 1).

Tabla 1: Descripción de Punción Lumbar con Líquido Cefalorraquídeo

\begin{tabular}{ccc}
\hline \hline Parámetro & Resultado & $\begin{array}{c}\text { Valor de } \\
\text { Referencia }\end{array}$ \\
\hline \hline Color & Claro cristalino & No aplica \\
Aspecto & Incoloro & No aplica \\
Leucocitos & 2.0 & x campo \\
Glucosa & $48.0 \mathrm{mg} / \mathrm{dL}$ & $(40.0-70)$ \\
Proteínas Totales & $69.9 \mathrm{mg} / \mathrm{dL}$ & $(15.0-40)$ \\
Hematíes & 75 & x campo \\
Hematíes frescos & 100 & x campo \\
PMN & No se observan & No aplica \\
Panel Viral Film Array & Varicela zoster virus (vzv detectado) & No aplica \\
\hline \hline \multicolumn{2}{c}{ Fuente: (Tomado del Hospital Universitario Clínica San Rafael) }
\end{tabular}

Encontrando en LCR Hiperproteinorraquia, con Film Array positivo para el virus de la Varicela zoster, Se inicia manejo con aciclovir endovenoso a dosis de $10 \mathrm{mg} / \mathrm{kg}$ cada 8 horas durante 10 días. En la hospitalización presentó disfagia, por lo que se indicó toma de endoscopia digestiva alta, la cual se realizó, evidenciando candidiasis esofágica. Ante estos hallazgos se inició fluconazol $200 \mathrm{mg}$ vía oral por 10 días. Se descartaron alteraciones oftalmológicas. Debido a la aparición de lesiones vesiculares y secreción purulenta por conducto auditivo derecho recibió antibiótico y corticoide tópico. Presentó mejoría con evolución neurológica satisfactoria, y luego de completar 7 días de tratamiento antiviral fue enviada para hospitalización en casa y culminar el tratamiento pactado, luego de 12 días de hospitalización que requirió para resolución de los síntomas.

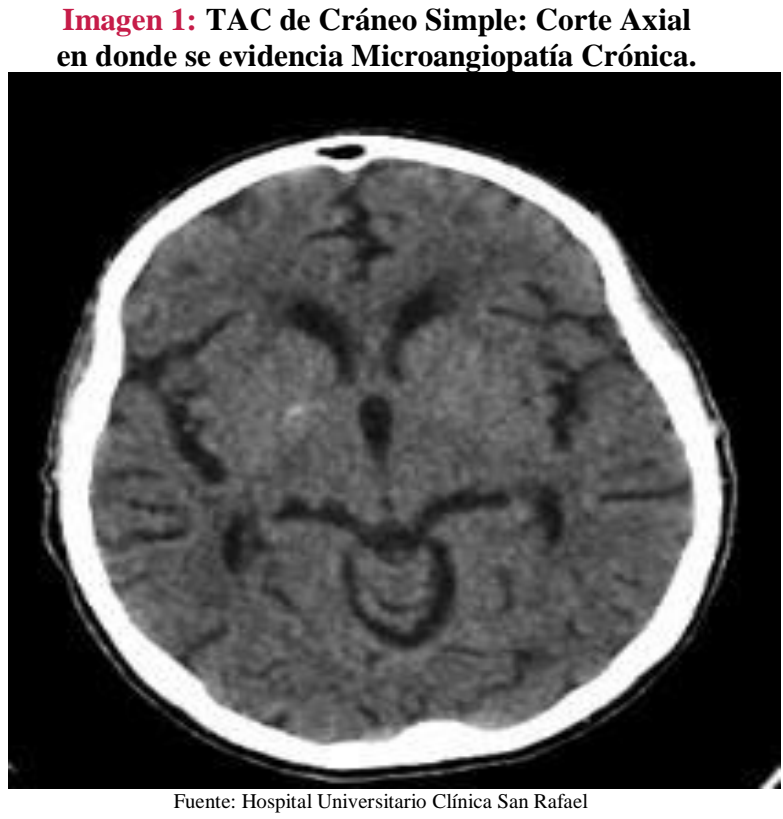


Imagen 2: RM de cerebro simple: corte axial de imágenes en FLAIR. Cambios involutivos del parénquima encefálico. Microangiopatía de la sustancia blanca subcortical y periventricular supratentorial.

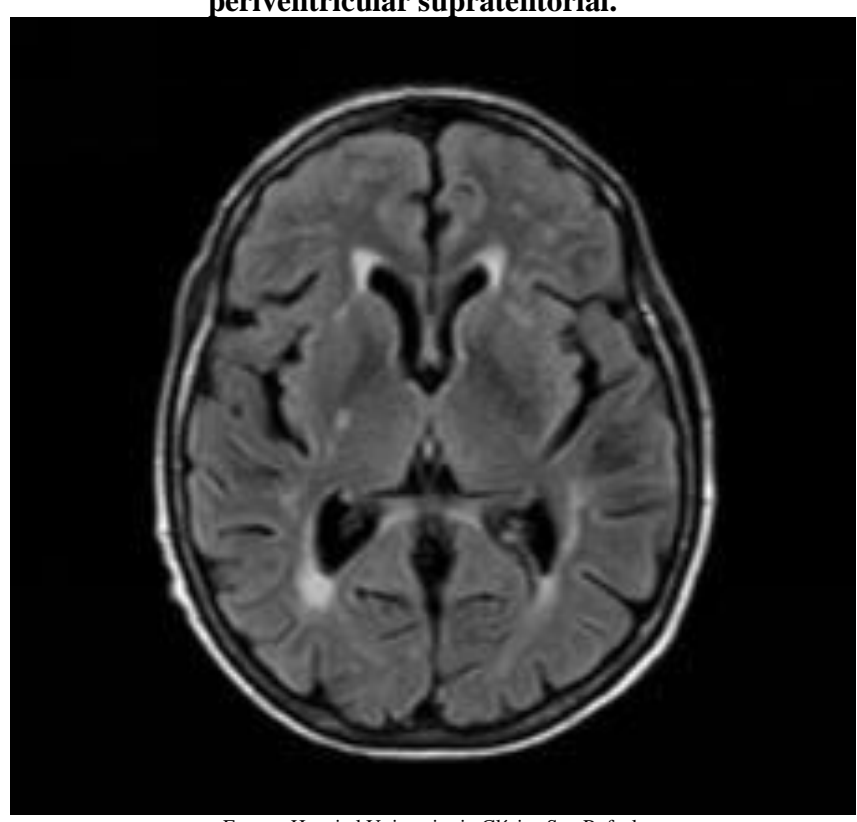

Fuente: Hospital Universitario Clínica San Rafael

Imagen 3: RM de cerebro simple: corte axial de imágenes en FLAIR. Cambios involutivos del parénquima encefálico.

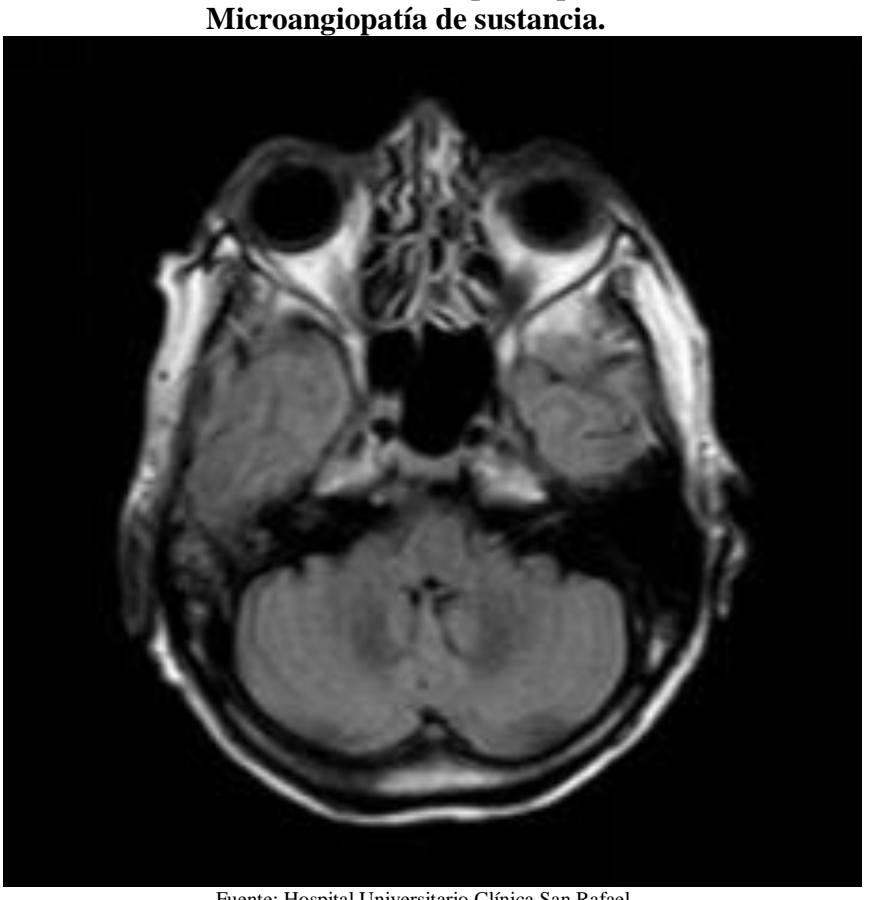

Fuente: Hospital Universitario Clínica San Rafael

A continuación, se ilustra el curso de la evolución de la enfermedad en la paciente (Figura1).
Figura 1: Orden Cronológico de la Enfermedad.

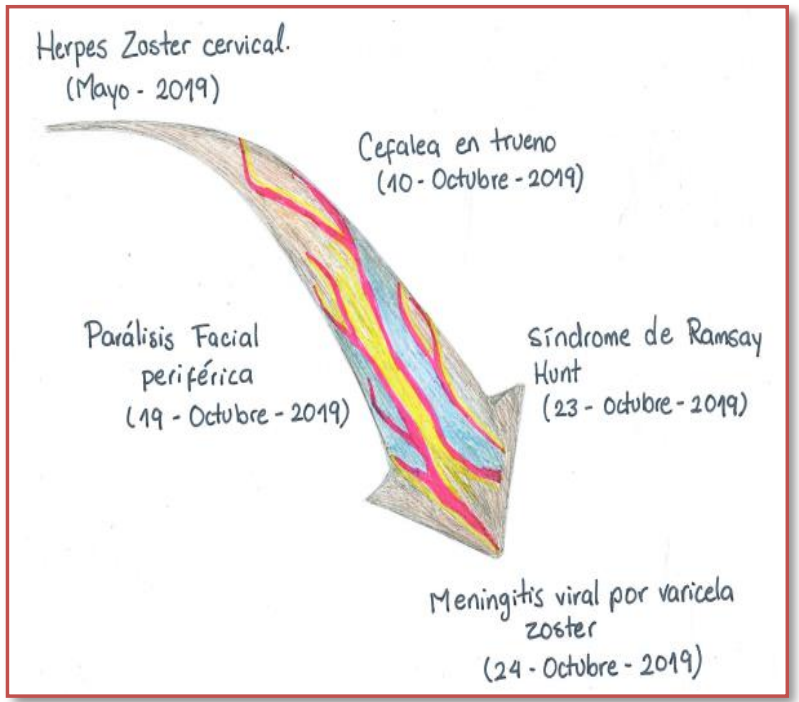

Fuente: Figura realizada por los autores.

\section{DISCUSIÓN}

El virus de la VZ se puede presentar de múltiples formas tras una reactivación, por lo que es importante considerar que puede comprometer SNC, causando encefalitis, meningitis, cerebelitis, mielitis, vasculopatías, y parálisis de los nervios craneales, incluido el síndrome de Ramsay Hunt.

El Ramsay Hunt es un síndrome clínico que se manifiesta como una reactivación del virus de la Varicela zoster, que posterior a la primoinfección permanece latente y se puede reactivar afectando principalmente el nervio facial (4). Fue inicialmente descrito en una mujer de 58 años, de Addis Abeba (capital de Etiopía), que presentó erupciones vesiculares en el pabellón auricular derecho, seguido de paresia facial ipsilateral y otalgia (4).

\section{Epidemiología}

El SRH, no es una patología infrecuente. Se contabiliza la presencia de Herpes zoster con parálisis facial en aproximadamente 4.5 a $8.9 \%$ de los casos (4). En un estudio realizado en San Francisco, Norte de California, identificaron 1507 pacientes, con parálisis facial y de ellos 185 pacientes fueron diagnosticados con SRH; realizando aislamiento viral en tan sólo el $25 \%$ de los casos (5). En este mismo estudio, de acuerdo con la población estudiada, la distribución por edades, encontraron una mayor frecuencia en las primeras décadas de la vida, específicamente entre los 0-24 años, se contabiliza un $30.27 \%$ de los casos y con una relación inversamente proporcional conforme aumenta la edad (6).

Las personas que hayan padecido varicela tienen una probabilidad del $20 \%$ de desarrollar Herpes zoster. Se observa una mayor frecuencia en mujeres con una relación de 1.3:1, sin 
embargo, otros estudios informan que la relación de proporción es igual (3).

\section{Etiología}

La infección es ocasionada por el virus de la Varicela zoster, que pertenece a los alfaherpesvirus, caracterizados por afectar principalmente a las estructuras nerviosas, su tamaño es de 120 a 200 nm, su morfología es por una molécula de ADN de doble cadena (3).

\section{Fisiopatología}

Se requiere que exista una primo infección de la mucosa respiratoria con replicación en los ganglios linfáticos regionales. Hay un paso del virus de los linfocitos $\mathrm{T}$ al sistema reticuloendotelial; posteriormente se da una afección de las células endoteliales de los capilares de la piel, y replicación de los queratinocitos produciendo las lesiones características típicas. Cuando termina la infección, el virus queda latente en el ganglio geniculado o de la raíz dorsal (3).

\section{Presentación clínica}

La presentación clásica, se expresa con Herpes zoster ótico, acompañado de parálisis facial periférica, náuseas, vértigo, tinnitus, pérdida de la audición y nistagmo (6).

Malin y colaboradores, definieron unos criterios específicos encontrados en estos pacientes: Zoster Oticus (lesiones raramente vistas también en paladar blando), parálisis periférica del nervio facial con alteración del gusto, disminución del lagrimeo, alteración de la sensibilidad de la primera y la tercera rama del trigémino, así como alteración de la sensibilidad en los dermatomas de $\mathrm{C} 2$ a $\mathrm{C} 4$, lesión del nervio acústico y del nervio vestibular (7). En el estudio realizado en California, los 185 pacientes diagnosticados con Ramsay Hunt presentaron diferentes síntomas, el más prevalente fue el dolor (98\%), disgeusia $(65,68 \%)$, epifora $(53,92 \%)$, hiperacusia $(50.98 \%)$, disminución de lagrimeo (42.15\%), pérdida auditiva $(20.58 \%)$ (5).

Se describen 4 fases clínicas que se relacionan con la replicación viral:

Estadio I: Inicia con otalgia y vesículas en territorio del nervio facial. (Figura 2).

Figura 2: Síndrome de Ramsay Hunt

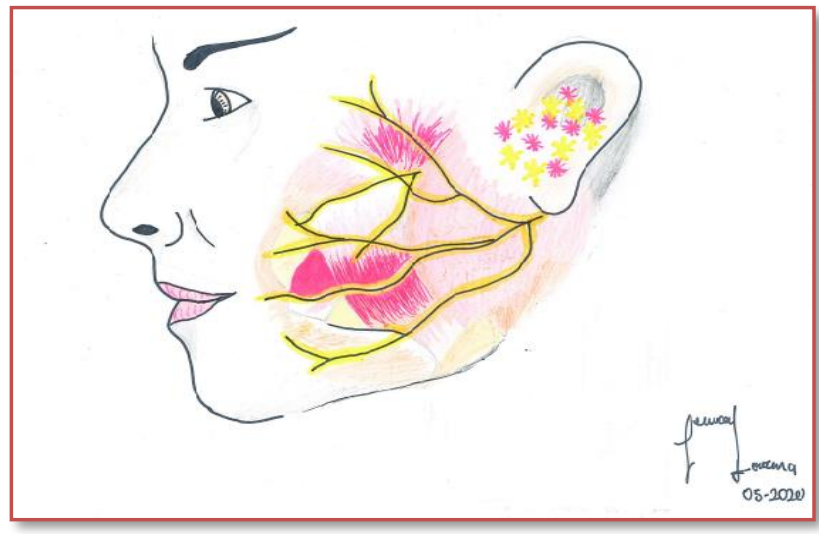

Fuente: Realizada por los autores
Estadio II: Asociado a lo anterior aparece una parálisis facial periférica homolateral (Figura3).

Figura 3: Parálisis facial Periférica

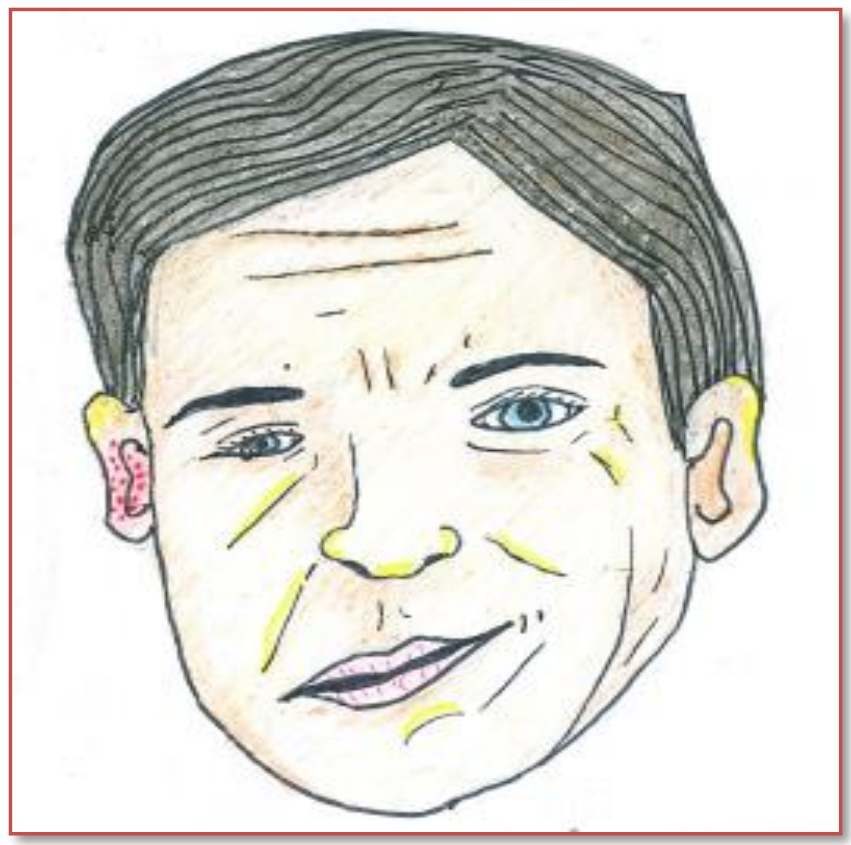

Fuente: Realizada por los autores.

Estadio III: (Síndrome de Sicard): triada de dolor, erupción y parálisis facial, acúfenos, hipoacusia, y crisis vertiginosas (Figura 4).

Figura 4: Síndrome de Sicard

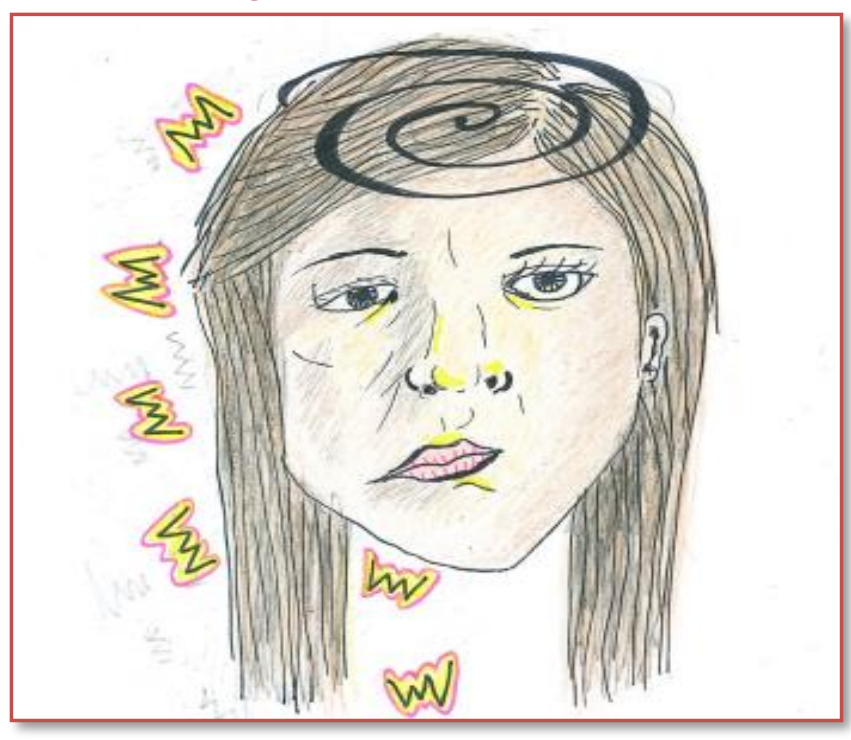

Fuente: Figura realizada por los autores 
Estadio IV: Alteración de otros pares craneales, el V par (5) (6). (Figura 5).

Figura 5: Compromiso del V par

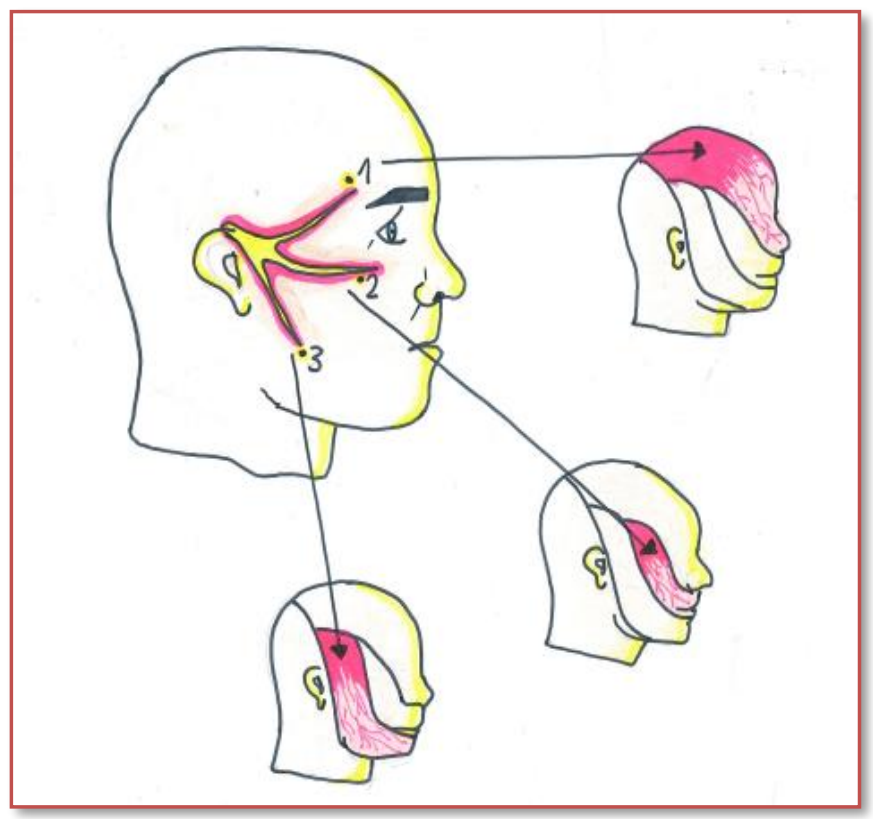

Fuente: Realizada por los autores.

\section{Lesiones de pares craneales}

La afectación del VII par craneal ocasiona la parálisis facial periférica. Si el compromiso del nervio es proximal el paciente cursa con epífora, hiperacusia y ageusia (8). Cuando existe afectación del octavo par craneal, la dividimos en rama coclear con hipoacusia y acúfeno. Cuando se afecta la rama vestibular aparece vértigo, náusea, vómito y nistagmo. Los trastornos de la deglución aparecen cuando hay daño en el X par (8).

\section{Reactivaciones clínicas}

La reactivación clínica ocurre como consecuencia de disminución de la respuesta inmune celular, los pacientes ancianos, tienen un mayor número de viremia secundaria. Se describen reactivaciones con patologías como meningitis, encefalitis y mielitis (9).

En un estudio realizado en California Encephalitis Project (CEP), donde se analizaron 4290 muestras de líquido cefalorraquídeo, se encontraron 26 pacientes positivos para varicela zoster. Además, en los espectros clínicos del compromiso del sistema nervioso central de ese mismo estudio encontraron un $50 \%$ como meningitis, $42 \%$ como encefalitis, $8 \%$ como encefalitis aguda diseminada (9).

En un estudio realizado en Bélgica por Gregoire y colaboradores de pacientes con virus de Varicela zoster e infección del sistema nervioso central, la edad promedio de presentación de los síntomas fue de 53 años; tan sólo el 29\% de ellos tenían inmunocompromiso. Al realizar las pruebas diagnósticas, se encontró que la reacción en cadena de polimerasa (PCR), fue positivo sólo en el $44 \%$ de los pacientes (10).
Son factores de mal pronóstico la edad avanzada, la hipertensión arterial, el vértigo y la diabetes (11).

Reactivaciones patológicas

\section{Meningitis}

Cuando se trata de meningitis, causada por virus de la VZ, se registra como una de las principales afectaciones en el sistema nervioso central, se cuantifica en un 4.4 a un $11 \%$, diagnosticado por reacción en cadena de polimerasa. Existen distinciones de acuerdo con el origen viral. En adultos es principalmente por Herpes zoster y en niños ocasionado por reactivación del virus de la Varicela zoster (2).

Se caracteriza clínicamente por presentar cefalea, fiebre y rigidez en el cuello, en algunos casos se asocia a alteración del estado de conciencia, convulsiones, síntomas que, si se presentan, se debe sospechar la presencia de encefalitis.

Igualmente, la afectación meníngea se puede dar con o sin erupción cutánea (12).

\section{Diagnóstico}

El diagnóstico se debe realizar por la clínica, la anamnesis y el examen físico. Si bien es cierto, los antecedentes clínicos nos deben apoyar en el diagnóstico. Comúnmente se piensa que el compromiso neurológico, se observa en pacientes inmunocomprometidos; sin embargo, la literatura describe afectación en pacientes inmunocompetentes, especialmente en menores de 60 años con un porcentaje que va desde el $10 \%$ al $38 \%$ (13).

Los hallazgos de laboratorio en suero son inespecíficos, ya que la mitad de los pacientes que presentan meningitis por virus de la Varicela zoster tiene leucocitos normales en el LCR (13). El análisis de LCR es inespecífico e inexacto, y no sigue una regla exacta, sin embargo, como lo describe Hikebwaba y colaboradores, donde citan los hallazgos descritos por Harrison's Principles of Internal Medicine, en el que se observa, pleocitosis linfocítica, concentración normal o ligeramente elevada de proteínas, glucosa normal y presión de apertura normal o moderadamente elevada (14).

Particularmente la mediana del recuento de proteínas en LCR causado por el virus de Varicela zoster ( $974 \mathrm{mg} / \mathrm{L})$, es mayor, si lo comparamos, por ejemplo, con el enterovirus $(640 \mathrm{mg} / \mathrm{L})$ (9). La media del recuento leucocitario del LCR puede ser mayor en meningitis por VZ (207 leucocitos/litro) comparado con el enterovirus (51 leucocitos/litro), lo que podría ayudar a orientar el diagnóstico (14).

\section{Hallazgos de RM de cerebro}

Habitualmente la infección por el VVZ produce un incremento en la señal del segmento canalicular y del ganglio geniculado por el proceso inflamatorio que genera, además del fenómeno compresivo. El agujero meatal, que conecta el conducto auditivo interno con el nervio facial, es la porción más 
estrecha del nervio facial, como tal, está sujeta a la presión más alta (15).

En secuencias de T2 está reportado el engrosamiento del segmento distal del nervio intrameatal (15). En FLAIR se pueden observar cambios en los nervios craneales y en el oído interno debido a la alta concentración de proteínas y reforzamiento anormal con el contraste. En esta secuencia se ha evidenciado afección coclear y del vestíbulo en el $29 \%$ de los casos de la RM sin contraste y el 7\% con contraste (16). En las secuencias de difusión, se pueden ver áreas de restricción (17).

En la RM contrastada hay un realce del nervio facial en el $50 \%$ de los casos (18). Los segmentos de mayor realce en forma descendente son el laberíntico $(84 \%)$, la región intracanalicular $(69 \%)$ y el ganglio geniculado $(69 \%)$. Además, se ha descrito realce intenso de los segmentos timpánicos y mastoideos del nervio facial (19) (20). Después de la administración del medio de contraste se puede observar realce del nervio vestibular, de la cóclea, el vestíbulo y de los canales semicirculares (19) (21).

El realce puede persistir por semanas y meses, incluso en pacientes con recuperación clínica completa (22).

\section{Diagnóstico diferencial}

Incluye comúnmente la parálisis de Bell, que se resuelve espontáneamente. La neurosarcoidosis que puede comprometer el nervio facial en un 5-10\% de los pacientes (4). El síndrome de Parry Romberg, es una atrofia progresiva del nervio facial, de probable etiología autoinmune, más común en mujeres y se asocia a degeneración del tejido blando del lado afectado de la cara. Otras etiologías son la otitis externa y la neuralgia del trigémino (23).

\section{Complicaciones}

Diferentes secuelas neurológicas post herpéticas, se han descrito tales como la neuralgia postherpética, caracterizada por dolor urente de intensidad severa, alodinia sobre el dermatoma afectado, asociado a ansiedad, síntomas depresivos, mal patrón de sueño, por lo que es importante el oportuno reconocimiento, debido a que afecta la calidad de vida y requiere tratamiento adicional con neuromoduladores.

Otras complicaciones para tener en cuenta son las dermatológicas, como las infecciones por estafilococos, y estreptococos, debido a que requieren tratamiento antibiótico adicional. Menos frecuentemente se ha descrito el linfoide atípico, la dermatofitosis, el linfoma linfoplasmocitoide, el linfoma de células $\mathrm{T}$, la leucemia cutánea, el sarcoma de Kaposi, el pseudolinfoma, la dermatitis y vasculitis granulomatosa. Así mismo cabe destacar la meningitis, la encefalitis, la cerebelitis, la mielitis y la vasculopatía (24).

\section{Prevención}

El HZ con lesiones vesiculares puede ser contagioso y provocar varicela en personas seronegativas y no inmunes por contacto directo. El riesgo de transmisión es mayor cuando las lesiones se encuentran en la fase maculopapular, por lo que cubrir las lesiones hasta que se han formado las costras, puede ser una medida de prevención primaria para contactos inmunocomprometidos. Actualmente, para la prevención, se cuenta con una vacuna disponible comercialmente aprobada por la FDA y el INVIMA (4).

\section{Tratamiento}

Existen pocos estudios para el tratamiento de meningitis viral por el virus de la Varicela zoster, ciertos autores consideran que no existe beneficio de iniciar tratamiento en los pacientes que desarrollan meningitis secundaria al virus de la Varicela zoster (25).

Sin embargo, se recomienda iniciar tratamiento antiviral si hay erupción con la enfermedad; el uso de corticoides es útil, previniendo y disminuyendo el edema y la posible aparición de neuralgia postherpética (25).

En la revisión de Kangath y colaboradores, consideran dar tratamiento combinado con ceftriaxona, vancomicina y aciclovir intravenoso, antes del reporte de líquido cefalorraquídeo; si se descarta patología bacteriana se debe suspender el cubrimiento antimicrobiano. Se indica tratamiento antiviral con aciclovir dosis $10 \mathrm{mg} / \mathrm{kg}$ cada 8 horas por 7 días $\mathrm{y}$ se continúa tratamiento con valaciclovir oral durante 2 semanas más (26).

Se indica tratamiento con aciclovir, antiviral de elección, nucleósido de purina acíclico, que, por lo general, tiene pocos efectos secundarios, sin embargo, se asocia a aparición de lesión renal aguda cuando se administra de forma intravenosa principalmente en ancianos (3). La administración por vía oral no se recomienda cuando existe afectación del sistema nervioso central, ya que la biodisponibilidad es pobre, cerca del $50 \%$, de los niveles que se alcanzan en plasma (3).

\section{Pronóstico y Recuperación}

Según Coulson y colaboradores en 2011, diseñaron un estudio de cohortes de sólo pacientes con Síndrome de Ramsay Hunt, en donde describen que el $59 \%$ de sus pacientes presentaron una recuperación satisfactoria, sin embargo, la mayoría al final del año estaban recuperados; observaron que la presencia de diplopía y alteraciones en la deglución fueron factores de mal pronóstico, que hacen sospechar compromiso del sistema nervioso central (27).

La mortalidad de meningitis por varicela zoster varía del 5 al $15 \%$ en pacientes inmunocompetentes; en pacientes con VIH la mortalidad sube hasta el 33\%. Las secuelas neurológicas en los que sobreviven van del 10 al 50\%, y constan de alteraciones neuropsicológicas y síndromes convulsivos (27).

Se considera relevante el caso debido a que se relata la historia cronológica de una paciente quien debutó con Herpes zoster cervical, cefalea en trueno, parálisis facial periférica, Síndrome de Ramsay Hunt y meningitis viral por varicela, ilustrando los múltiples espectros del Virus de la Varicela zoster. 


\section{CONCLUSIONES}

El virus de la Varicela zoster, se puede reactivar después de una primoinfección, produciendo diferentes síndromes clínicos que comprometen el sistema nervioso central y periférico, tales como meningitis, encefalitis, cerebelitis, compromiso de pares craneales, mielopatía, vasculopatía, y neuralgias, por lo que su diagnóstico oportuno y tratamiento temprano son importantes para una evolución clínica favorable de los pacientes que cursen con una reactivación.

Conflicto de Interés: Los autores no declaran conflicto de interés.

Consentimiento para Publicación: Se obtuvo el consentimiento informado por escrito del paciente para la publicación de este reporte de caso, y las imágenes que lo acompañan, así como la aprobación del comité de ética del Hospital Universitario Clínica San Rafael. Una copia del consentimiento, y de la aprobación por parte del comité de ética por escrito está disponible para revisión.

\section{Abreviaturas: \\ L HZ: Herpes zoster \\ VVZ: Virus de la Varicela zoster \\ VZ: Varicela zoster \\ SRH: Síndrome de Ramsay Hunt \\ LCR: Líquido cefalorraquídeo \\ SNC: Sistema nervioso central \\ PCR: reacción en cadena de polimerasa}

Agradecimientos: Los autores quieren agradecer al grupo de docencia e investigación, a la dirección científica y general del Hospital Universitario Clínica San Rafael, así al departamento de medicina interna por su apoyo en el manuscrito de este documento; así como a la artista y realizadora gráfica Jessica Lorena Vásquez García por la creación de las figuras 1, 2, 3, 4, 5 , quien cedió los derechos de autor para el caso en mención.

\section{REFERENCIAS}

1. Parey LA. Artículo de revisión Herpes zoster. 2011;55(1):24-39.

2. Jeon Y, Lee H. Ramsay Hunt syndrome. Journal of Dental Anesthesia and Pain Medicine. 2018;18(6):333.

3. Grahn A, Studahl M. Varicella-zoster virus infections of the central nervous system - Prognosis, diagnostics and treatment. Journal of Infection. 2015;71(3):281293.

4. Zaragoza-Velasco $\mathrm{K}$, Martínez-Gudiño $\mathrm{M}$ de $\mathrm{L}$, Robles-Ramírez F. Síndrome de Ramsay Hunt: revisión de la literatura y hallazgos por resonancia magnética. Rev An Radiol México. 2020;19(1):50-9.

5. Robillard RB, Hilsinger RL, Adour KK. Ramsay Hunt facial paralysis: Clinical analyses of 185 patients. Otolaryngol - Head Neck Surg. 1986;95(3 I):292-7.

6. Kunitomo K. Ramsay Hunt syndrome. Postgrad Med J. 2019;18(6):333-7.
7. Gunnar Wagner, Harald Klinge MMS. Ramsay Hunt syndrome. J or Ger Soc dermatology. 2012;10(1):23843.

8. YL BRL y RA. Síndrome de Ramsay Hunt: informe de dos casos y revisión de la bibliografía. Rev Espec Médico-Quirúrgicas. 2014;19(2):192-9.

9. Felipe Vial U, Sofía González TK, Mirta Javiera López G. Caso clínico de una meningitis por reactivación del virus varicela zóster en un paciente inmunocompetente. Rev Chil Neuropsiquiatr. 2013;51(3):198-200.

10. Gregoire SM, Van Pesch V, Goffette S, Peeters A, Sindic CJM. Polymerase chain reaction analysis and oligoclonal antibody in the cerebrospinal fluid from 34 patients with varicella-zoster virus infection of the nervous system. J Neurol Neurosurg Psychiatry. 2006;77(8):938-42.

11. Colmenares AGEM. Síndrome de Ramsay-Hunt: ¿qué tratamiento precisa? 2011;37(8):436-40.

12. Gilden D, Cohrs R, Mahalingam R, Nagel $M$. Neurological Disease Produced by Varicella Zoster Virus Reactivation Without Rash. Current Topics in Microbiology and Immunology. 2010;243-253.

13. Becerra JCL, Sieber R, Martinetti G, Costa ST, Meylan $\mathrm{P}$, Bernasconi E. Infection of the central nervous system caused by varicella zoster virus reactivation: A retrospective case series study. Int $\mathrm{J}$ Infect Dis. 2013;17(7): e529-34.

14. Ihekwaba UK, Kudesia G, McKendrick MW. Clinical Features of Viral Meningitis in Adults: Significant Differences in Cerebrospinal Fluid Findings among Herpes Simplex Virus, Varicella Zoster Virus, and Enterovirus Infections. Clin Infect Dis. 2008;47(6):783-9.

15. Minakata T1, Inagaki A2, Sekiya S1, Murakami S1. Contrast-enhanced magnetic resonance imaging of facial nerve swelling in patients with severe Ramsay Hunt syndrome. Auris Nasus Larynx. 20149 oct;46(5):687-695.

16. Chung MS1, Lee JH, Kim DY, Lim YM, Ahn JH, Sung YS, Choi YJ, Yoon RG, Baek JH. The clinical significance of findings obtained on 3D-FLAIR MR imaging in patients with Ramsay-Hunt syndrome. Laryngoscope. 2015 Apr;125(4):950-5. doi: 10.1002/lary.24973. Epub 2014 Oct 27.

17. Ji Y1, Ma GM2, Kang ZL3, Zhang Y4, Han JZ2, Li J1, Wu DD1, Wang J1. Ramsay Hunt syndrome with pontine lesion: A case report. Medicine (Baltimore). 2019 feb;98(5): de 1426.

18. Korzec Kenneth M.D.; Sobol, Steven M. M.D.; Kubal, Wayne M.D.; Mester, Sara J. R.T.(R); Winzelberg, Gary M.D.; May, Mark M.D., F.A. C.S. Gadoliniumenhanced magnetic resonance imaging of the facial nerve in herpes zoster oticus and Bell's palsy: clinical implications. The American Journal of Otology: May 1991 - p 163-168.

19. Sartoretti-Schefer S, Wichmann W, Valavanis A (1994) Idiopathic, herpetic, and HIV-associated facial nerve palsies: abnormal MRI enhancement patterns. AJNR 15:479-485.

20. Tada Y1, Aoyagi M, Tojima H, Inamura H, Saito O, Maeyama H, Kohsyu H, Koike Y. Gd-DTPA enhanced MRI in Ramsay Hunt syndrome. Acta Otolaryngol Suppl. 1994; 511:170-4.

21. Yanagida M1. MRI enhancement of the facial nerve with Gd-DTPA--second report--investigation of enhanced nerve portions in patients with facial palsy. 
Nihon Jibiinkoka Gakkai Kaiho. 1993 Aug;96(8):132939.

22. Downie AC1, Howlett DC, Koefman RJ, Banerjee AK, Tonge KA. Case report: prolonged contrast enhancement of the inner ear on magnetic resonance imaging in Ramsay Hunt syndrome. Br J Radiol. 1994 Aug;67(800):819-21

23. Lin YT1, Shih PY1. Facial palsy in a 38-year-old man. Ramsay Hunt syndrome. Am Fam Physician. 2013 Dec 1;88 (11):771-2.

24. Amrita R. et al. Herpes Zoster in the Older Adult. Infect Dis Clin N Am 31 (2017) 811-8.

25. Ganesan V. Herpes Zoster Infection Involving Mandibular Division of Trigeminal Nerve and Ramsay Hunt Syndrome with Meningitis in an Immunocompetent Patient: A Rare Association. J Clin Diagnostic Res. 2016;10(6):7-9.

26. Kangath RV, Lindeman TE, Brust K. Herpes zoster as a cause of viral meningitis in immunocompetent patients. BMJ Case Rep. 2013;2012-3.

27. Coulson S, Croxson GR, Adams R, Oey V. Prognostic factors in Herpes Zoster Oticus (Ramsay Hunt syndrome). Otol Neurotol. 2011;32(6):1025-30. 